\title{
Professor Alexander Heinrich Gay
}

Reihe von Patienten in einer für dieselben überraschenden Weise nützlich werden.

Das Nosophen, welches auf die Anregung von Claassen undLoeb durch die chemische Fabrik Rhenania in Aachen in Vertrieb gebracht worden ist und dessen $\lambda$ vi i in dieser Zeitschrift bereits einmal Erwähnung gethan haben, stellt sicli mehr und mehr als ein wirksames $\Lambda$ Vnndpulver heraus, dem aucli jetzt nach jahrelangem G-ebrauch Nachteile nicht nach-gesagt $\Lambda$ verden können. Das Pulver haftet auch an glatten und ab-schüssigen Oberflächen und ist deshalb vorwiegend nacli Eingriffen im Ge-sicht, die man mit einem trockenen Schorf abheilen will, zu empfehlen. Nach Scarifícationen, Stichelung, Thermocauter- oder Galvanocauter-Verwendung pflegt sich dasselbe bestens zu bewähren. Vielleicht hat der weiteren Ver-breitung des Präparates bisher noch der verhältnismässig hohe Preis ent-gegengestanden. Jedoch bedarf es für die Verwendung nur geringer Quantitäten.

Die Wiener Dermatologisehe Gesellsehaft hat den Herausgeber dieser Zeitschrift, Professor Dr. 0. Lassar, durch Ernennung zu ihrem Ehren-Mitgliede einer hohen Auszeichiíung gewürdigt. Professor Alexander Heinrich Gay vollendet am $1 / 829$. Dezember (=10.Januar) sein dreissigstesDienstjahr alsDirektor und Vorstand der Dermatologischen Klinik zu Kasan. $\Lambda$ Vir bringen diesem ausgezeichneten Collegen und Forscher unsere herzlichen Glückwünsche dar. Seine vorzüglichen Arbeiten iiber die Anatomie der Prurigo und der Drüsen, sein in Russland überall verbreitetes Lehrbuch der venerischen Krankheiten und zahlreiche andere Publikationen haben ihn in der ganzen A.erzte- $\Lambda$ Velt bekannt gemacht. $\Lambda$ Ver das Glück hat, ihm persönlich zu bogegnen, wird in Herrn Gay einen der menschenfreundlichsten und gelehrtesten Fachge-nossen kennen lernen. Ein treuer Sohn seiner engeren Heimat hat or in seiner Vaterstadt Kasan studiert, promoviert und sich habilitiert und nimmt jetzt eine der ersten Stellungen Russlands als akademischer Lehrer ein. Möge dem in der Yollkraft seines Lebens schaffenden Manne noch ein langer und segensreicher $\Lambda$ Virkungskreis beschieden sein. 